\title{
Entretener y vender, ¿fatal destino \\ de la televisión mexicana?
}

Delia Crovi Druetta

Facultad de Ciencias Politicas y Sociales

UNAM

\section{Antecedentes}

EL PRESENTE análisis forma parte de una investigación más amplia acerca de la influencia que sobre la televisión ejercen las políticas neoliberales en México. ${ }^{1}$ El periodo estudiado abarca desde 1982, año en que se ubica el surgimiento de esas políticas, hasta la actualidad; en tanto que el universo escogido son los 19 millones de habitantes de la ciudad de México y su área conurbada que consideramos están en condiciones de recibir señales televisivas. (WISA, 1992) El Distrito Federal no sólo reviste importancia por ser la capital del país, sino que es el centro urbano desde donde se emiten todas las señales de las cadenas televisivas con cobertura nacional y por lo tanto, desde donde se establecen las normas no escritas de la televisión mexicana.

El avance alcanzado hasta ahora en la investigación permite situar cinco ejes en los cambios experimentados por la televisión mexicana a partir del neoliberalismo:

1 Entendemos por políticas neoliberales a las implementadas sobre todo a partir de los años ochenta que se distinguen, entre otras cosas, por: reemplazo del Estado de bienestar por un bienestar del mercado; modernización económica y competitividad regional; reformulación del cuerpo normativo con el propósito de sustentar la nueva concepción del Estado; nuevos valores y relaciones sociales generados en el mercado; despolitización del ambiente social; nuevo orden social que desplaza a las clases para centrarse en la familia y el individuo; sobrevaloración del futuro en detrimento del presente y pasado; democracia controlada a través de algún sistema de elecciones. 
a) Privatización de los sistemas públicos, lo cual originó que el 10 de diciembre de 1991 apareciera en el Diario Oficial de la Federación el decreto por el cual desapare cía del Instituto Mexicano de Televisión(Imevisión), que había sido creado por el Estado mexicano el 24 de marzo de 1983 junto con los Institutos de la Radio y de Cine (Imer e Imcine, respectivamente). ${ }^{2}$ Esto permitió un largo proceso de privatización que culmina en julio de 1993 con la adjudicación de los canales 7 y 13, así como sus 189 estaciones repetidoras, a la empresa Televisión Azteca, la cual pagó por la adquisición 640 millones de dólares. El nuevo sistema de televisión inicia así, una incipiente competencia con el consorcio Televisa que hasta entonces monopolizaba las señales privadas de la televisión capitalina.

b) Cambios sustantivos en los canales culturales 11 y 22 , únicos que quedan en manos del Estado, básicamente en tres aspectos: programación; venta de espacios publicitarios y recomposición de los grupos que diseñaban y producían los contenidos. ${ }^{3}$ Recordemos que ambos canales a partir de 1990 reformulan su organización interna, lo cual provoca numerosos despidos de personal. Al mismo tiempo, se producen cambios sustantivos en la programación que, sobre todo en el caso del 11, se distingue por la adquisición de series extranjeras con una producción local menor. Además, y sin las correspondientes modificaciones a la legislación vigente que impide a los permisionarios introducir publicidad en sus emisiones, en la actualidad ambos canales incluyen anuncios comerciales bajo la eufemística denominación de patrocinios. En el caso específico del Canal 22, vale la pena recordar que originalmente había sido incluido en el paquete de medios para su privatización. Sin embargo, el 26 de enero de 1991 un grupo de 800 intelectuales solicitan a través de un comunicado público, que ese canal se destine a la cultura, pedido que es atendido afirmativamente 20 días después, integrándose un consejo de planeación para su puesta en marcha, cosa que se concreta casi dos años y medio después: el 1 de julio de 1993.

2 Para más información sobre el proceso privatizador de la televisión mexicana ver: Crovi Druetta, Delia (1993): "Libre comercio en televisión...fantasía de diversidad". Revista Mexicana de Ciencias Politicas y Sociales Núm. 154, México: UNAM (oct.-dic.), y Florence Toussaint (coord.) (1993), ¿Televisión pública en México? México: Conaculta, Col. Pensar la Cultura.

3 Para ampliar información sobre los cambios experimentados por Canal 11 y Canal 22 en los últimos años, puede consultarse la bibliografía sugerida en la nota anterior. 
c) Aumento de la oferta de televisión de paga a través de: Cablevisión, empresa de televisión por cable perteneciente a Televisa que en tan sólo dos años triplicó su número de canales y Multivisión, servicio de señal restringida surgido en 1989. Entre ambas empresas se inaugura una dura competencia por ganar suscriptores.

d) Fortalecimiento de una televisión clasista que privatiza el acceso a los mensajes.

e) Fortalecimientọ de las tendencias monopólicas nacionales y trasnacionales.

\section{Alcance de estas reflexiones}

Estas reflexiones se centrarán en la programación televisiva de la ciudad de México, con lo que dejamos de lado el proceso privatizador de la televisión; el marco teórico de la relación televisión-neoliberalismo; así como un análisis cualitativo de la audiencia que también forman parte de la investigación. No obstante, pensamos que analizar la programación como uno de los elementos que intervienen en el complejo proceso de la comunicación televisiva es fundamental, ya que es a través de ella que se juegan no sólo los costos de producción, la publicidad, los contenidos globales de cada canal y su caracterización general; sino también la selección que los receptores realizan sobre una oferta más o menos variada de programas.

La programación constituye una suerte de mapa dentro del cual, aparentemente, el receptor ejerce su libertad escogiendo aquello que le interesa ver. Aun cuando esta libertad, como sabemos, está predeterminada por las propuestas que formulan las empresas televisivas, los anuncios sobre programación que aparecen en periódicos y revistas especializadas, constituyen un punto de partida para la elección de lo que puede verse en televisión.

A partir del fortalecimiento de los sistemas de televisión de paga debemos distinguir dos clases de oferta: la tradicional de los canales abiertos, que busca a lo largo del día y explorando diferentes géneros y formatos, ofrecer a los receptores un menú variado en un solo canal; y la que podríamos definir como una televisión temática. Esta última se ha generalizado a través de los sistemas de paga y abarca, por canales, temas tales como deportes, noticias, cine, telenovelas, programas infantiles, musicales, entre otros.

Si bien es cierto que los sistemas de paga pueden ofrecer programas variados en algunos de sus canales o incluir, por ejemplo, algunostalkshows en sus musicales, 
la característica general de este servicio televisivo es identificar a cada canal con un tema, lo que permite al espectador obviar, del alguna manera, la consulta de las programaciones por horario. Esta televisión "a la carta" como se la ha llamado, busca constituirse en una especie de panacea de la libertad para escoger que puede ejercer el televidente y ese es su principal argumento de venta.

En ambos casos, televisión a la carta o programación variada, debemos tener muy presente que construir una programación supone una concepción previa de cierto de tipo de televisión. Así, una de las diferencias básicas, hoy un tanto desdibujada, entre los modelos de televisión privada y pública, es que mientras la primera se define por su rentabilidad, la segunda puede ordenar sus contenidos al margen de las presiones que impone el rating. Analizar la programación de los canales de la ciudad de México, pretende entonces, desentrañar en parte esa concepción previa de televisión que poseen los canales capitalinos.

Los datos que presentamos se derivan del estudio de programación realizado durante la semana del 5 al 11 de marzo de 1994, en la televisión abierta y en la de paga. ${ }^{4}$ Para entonces la oferta de televisión abierta en México era de ocho canales: seis privados y dos del Estado, culturales. La televisión de paga ofrecía un total de 43 canales, 23 de cable y 20 de señal restringida. Véase el cuadro 1.

Con el propósito de ser operativos, determinamos siete categorías de análisis arbitrarias que nos permitieran reconocer las tendencias dominantes en la oferta televisiva: información-opinión, ficción, infantiles, educativos, variedades, deportes y ventas. $^{5}$

4 Se tomó como segmento de análisis una semana de programación, debido a que esta es la unidad de tiempo empleada por las televisoras para construir sus propuestas temáticas. Marzo fue el mes escogido porque en general los cambios de programación se reálizan entre enero y febrero, para una propuesta que debido a razones de costo, debe durar no menos de seis meses o 52 semanas. Será interesante en el futuro, realizar otros análisis semanales de programación, a fin de detectar cambios y tendencias.

5 Debido a la dificultad que encierra el escoger categorías apropiadas para el análisis televisivo, empleamos siete arbitrarias que no responden a los mismos criterios: información-opinión se basa en razones de género; infantiles se determina por su público; educativos, deportes y ventas por el contenido; mientras que variedades es un hibrido que responde a contenido y estructura de los programas. Cada una a su vez, se subdivide en otras que atienden sobre todo a razones de género. 


\section{Cuadro 1:}

Oferta de canales de televisión en el Distrito Federal

\begin{tabular}{|c|c|c|c|}
\hline \multicolumn{2}{|c|}{ Empresas y canales de televisión } & Abiertos & De paga \\
\hline Oficiales & 11 y 22 & 2 & \\
\hline Televisa & $2,4,5$ y 9 & 4 & \\
\hline Televisión Azteca & 7 y 13 & 2 & \\
\hline Cablevisión & $\begin{array}{l}6,12,14,15,16,17 \\
18,20,21,23,24,25 \\
26,27,28,29,30,31 \\
32,33,34,35 \text { у } 36\end{array}$ & & 23 \\
\hline Multivisión & $\begin{array}{l}1,3,6,8,10,12,14 \\
15,16,17,18,19,20 \\
21,24,25,26,27 \text { y } 28\end{array}$ & & 20 \\
\hline Totales & & 8 & 43 \\
\hline
\end{tabular}

FUENTE: elaboración de la autora

Estas categorías fueron cruzadas con dos ejes fundamentales para el estudio: origen de la programación y géneros o subcategorías. Véase cuadro 2.

\section{Cuadro 2:}

Categorías y subcategorías empleadas

\section{Categorías}

Información-opinión

Ficción

Infantiles

Educativos

Variedades

Deportes

\section{Subcategorías}

Noticieros-reportajes-revistas-talk shows-otros

Películas-series-telenovelas

Caricaturas-otros

Telesecundaria-divulgación

Musicales-concursos-humor-televerdad-otros Actividades deportivas-información deportiva Ventas 


\section{Televisión abierta}

En la semana estudiada la televisión abierta transmitió 922 horas con 45 minutos, de las cuales $557,82.5 \%$, son de la televisión privada (60.4\% de Televisa y $22.1 \%$ de Televisión Azteca), quedando sólo 17.5\%, 161.30 horas, en manos del Estado. ${ }^{6}$

En cuanto al contenido, ficción ocupa el primer lugar con $34 \%$ de la programación, colocándose las ventas en segundo término con $17 \%$ y muy cerca información-opinión, con $16.5 \%$ de las emisiones semanales. Véase cuadro 3.

\section{Cuadro 3:}

Horas transmitidas por categorías, según origen de la producción

\begin{tabular}{|lrrrrrr|}
\hline Categoría & $\begin{array}{c}\text { Nacional } \\
\text { (horas) }\end{array}$ & (\%) & $\begin{array}{c}\text { Extranjero (\%) } \\
\text { (horas) }\end{array}$ & TOTALES & (\%) \\
Ficción & $119: 00$ & 37.6 & $197: 00$ & 62.3 & $316: 00$ & 34.0 \\
Ventas & $158: 30$ & 100.0 & - & & $158: 30$ & 17.0 \\
Información-opinión & $139: 30$ & 91.4 & $13: 00$ & 8.6 & $152: 30$ & 16.5 \\
Infantiles & $38: 30$ & 37.5 & $64: 00$ & 62.5 & $102: 30$ & 11.0 \\
Educativos & $64: 30$ & 78.0 & $18: 15$ & 22.0 & $82: 45$ & 9.0 \\
Variedades & $41: 00$ & 71.6 & $16: 30$ & 28.4 & $57: 30$ & 6.5 \\
Deportes & $40: 30$ & 77.0 & $12: 30$ & 23.0 & $53: 00$ & 6.0 \\
TOTALES & $601: 30$ & 65.2 & $321: 15$ & 34.8 & $922: 45$ & 100.0 \\
\hline
\end{tabular}

FUENTE: Tele Guía Núm. 2169 y Reforma, marzo 5 a 11 de 1994.

El resto de los programas recibe menos atención: infantiles $11 \%$, educativos $9 \%$, variedades $6.5 \%$ y deportivos $6 \%$. Como veremos más adelante, esta distribución de categorías se repite con pocas variantes en la televisión de paga.

6 Para el análisis de programación se tomaron como fuentes básicas la revista Tele Guía y el periódico Reforma de la semana estudiada. Al mismo tiempo, se efectuó un monitoreo con el propósito de corroborar la información cruzada con anterioridad en las fuentes originalesy precisar las categorías donde debían incluirse los programas estudiados. 
Al cruzar las categorías con el origen de la programación, tenemos que $34.8 \%$ son programas producidos en el extranjero, lo cual deja $65.2 \%$ a la televisión nacional. Cuando nos referimos a programas extranjeros lo hacemos de una manera global, incluyendo en esta designación a toda producción que fue hecha fuera de México. Sabemos que hay un buen número de telenovelas producidas en países latinoamericanos, que muchos programas de caricaturas fueron realizados en Japón o en Francia, así como que las series en su mayoría son estadounidenses, sin embargo, esos datos no fueron desagregados.

Si hablamos de casi $65 \%$ de programación televisiva producida en el país, podríamos ver signos alentadores en esos datos, sin embargo, deben tomarse con cuidado. Por ejemplo ventas, la categoría que ocupa segundo lugar en contenidos, se produce íntegramente en México y no creemos que ello constituya un orgullo para la televisión nacionạl, debido a dos razones: a su pobre realización y a que su objetivo es apuntalar los negocios que en paralelo poseen las empresas televisivas, dedicados a vender productos diversos. De igual manera la información-opinión, que tiene un alto porcentaje de producción local, crece por el sistema ECO de noticias de Televisa producido en México pero con contenidos orientados hacia el extranjero donde tiene una importante audiencia.

En la categoría educativos destaca $64.3 \%$ de producción local. Sin embargo, esto se debe a telesecundaria, antiguo programa de educación no formal destinado a una audiencia muy restringida, que emite 30 horas semanales por la televisión abierta, o sea, $40 \%$ de esta categoría. En contraposición, si observamos la categoría infantiles, nos encontramos que $64 \%$ de las horas emitidas se producen fuera de México y en ficción, a pesar de ser México uno de los principales productores de telenovelas, el porcentaje global de origen extranjero aumenta debido a las películas.

En lo que respecta a variedades y deportes, no es extraño que destaque su producción local, ya que son los programas clásicos de entretenimiento que reciben mucha publicidad.

A nuestro juicio, estas observaciones exigen precisar en futuros análisis el concepto origen de la programación, estableciendo porcentajes por países productores y determinando otros factores que inciden sobre este eje como son los géneros y especialidades por naciones si es que se dan. Desagregar en el futuro este tipo de información, permitiría contar con datos sobre la calidad y especificidad de la producción televisiva por países, así como su temática, lo cual podría redundar en 
beneficio de un intercambio de producciones de televisión más rico y diversificado, en el marco de los procesos de libre comercio y globalizadores.

Respecto a qué sucede al interior de cada categoría, tenemos que en la primera, ficción, el mayor número de horas corresponde a películas, luego se colocan las series y finalmente las telenovelas. En todos los casos la producción extranjera predomina, sobre todo en las series que alcanza 93\%. Algo curioso ocurre con las telenovelas, ya que aún cuando Televisa es uno de sus principales productores, 45.5\% proviene de otros países latinoamericanos. Véase cuadro 4.

\section{Cuadro 4:}

Ficción según origen y subcategorías

\begin{tabular}{|c|c|c|c|c|c|c|}
\hline \multirow[b]{2}{*}{ Subcategorías } & \multicolumn{2}{|c|}{$\begin{array}{c}\text { Producción } \\
\text { nacional }\end{array}$} & \multicolumn{2}{|c|}{$\begin{array}{l}\text { Producción } \\
\text { extranjera }\end{array}$} & \multicolumn{2}{|c|}{$\begin{array}{c}\text { Totales } \\
\text { subcategorías }\end{array}$} \\
\hline & Horas & $(\%)$ & Horas & $(\%)$ & Horas & (\%) \\
\hline Películas & $77: 30$ & 45.0 & $96: 00$ & 55.0 & $173: 30$ & 54.9 \\
\hline Series & $5: 30$ & 7.0 & $71: 00$ & 93.0 & $76: 30$ & 24.2 \\
\hline Telenovelas & $36: 00$ & 54.5 & $30: 00$ & 45.5 & $66: 00$ & 20.9 \\
\hline TOTALES ORIGEN $\ldots$ & 119:00 & 37.6 & 197:00 & 62.3 & $316: 00$ & 100.0 \\
\hline
\end{tabular}

Es necesario aclarar que en la categoría ventas consideramos sólo programas destinados a vender, dejando fuera a los anuncios publicitarios. De incluirlos tendríamos 95 horas más, o sea, $27.4 \%$ del total de horas emitidas. Esto nos habla de una televisión orientada a la obtención de ganancias en la que uno de sus canales, el 4, emplea 20 horas al día para vender productos que en general son superfluos, además de programas de otros canales que ofrecen casas o automóviles.

Pensamos que esta categoría, de reciente surgimiento, busca aprovechar la conflictividad urbana de la ciudad de México - distancias excesivas, escasez de tiempo, inseguridad pública, deficiente transporte, entre otras razones - creando en sus receptores el hábito de las compras por televisión, a la vez de apuntalar, como ya se dijo, las ventas de las numerosas empresas que manejan tanto Televisa como Televisión Azteca. 
En cuanto a información-opinión, nos encontramos que dos terceras partes del tiempo de esta categoría se destina a noticieros producidos en México, aunque se nutren de las mismas agencias trasnacionales de información. Véase cuadro 5. Las revistas y reportajes también se producen en el país, pero su volumen es escaso. Con el propósito de registrar la evolución del talk show, un género incipiente aún en la televisión mexicana, incluimos el único programa de este tipo, producido en el exterior, que representa 5\% de la categoría.

\section{Cuadro 5:}

Información-opinión según origen y subcategorías

\begin{tabular}{|c|c|c|c|c|c|c|}
\hline \multirow{2}{*}{$\begin{array}{l}\text { Sublotor } \\
\text { Subcategorías }\end{array}$} & \multicolumn{2}{|c|}{$\begin{array}{c}\text { Produccion } \\
\text { nacional }\end{array}$} & \multicolumn{2}{|c|}{$\begin{array}{c}\text { Producción } \\
\text { extranjera }\end{array}$} & \multicolumn{2}{|c|}{$\begin{array}{c}\text { Totales } \\
\text { subcategorias }\end{array}$} \\
\hline & Horas & (\%) & Horas & $(\%)$ & Horas & $(\%)$ \\
\hline Noticiarios & $111: 30$ & 100.0 & - & - & $111: 30$ & 73.2 \\
\hline Revistas & $17: 30$ & 93.7 & $1: 15$ & 6.3 & $18: 45$ & 12.2 \\
\hline Reportajes & $7: 30$ & 65.0 & 4:00 & 35.0 & $11: 30$ & 7.5 \\
\hline Talk shows & - & - & $5: 00$ & 100.0 & $5: 00$ & 3.4 \\
\hline Otros & $3: 00$ & 55 & $2: 45$ & 45.0 & $5: 45$ & 3.7 \\
\hline TOTALES ORIGEN & $139: 30$ & 91.4 & 13:00 & 8.6 & $152: 30$ & 100.0 \\
\hline
\end{tabular}

FUENTE: Tele Guía Núm. 2169 y Reforma, marzo 5 a 11 de 1994.

El gran ausente en información-opinión es el debate, un género que en todas sus variantes, puede y debe incluir participación de especialistas o público con puntos de vista contrapuestos. Los debates como sabemos, implican controversia acerca de un tema, por lo que son programas de difícil control, tanto en lo que se dice como en quienes participan, por ello la televisión mexicana tiende a evitarlos, sobre todo en periodos de grandes contradicciones como son los preelectorales. Los cambios democráticos que se impulsan en el país, no deben dejar de ladolos debates televisivos en los que participen no sólo políticos, especialistas, académicos, intelectuales, sino que también permitan al espectador común participar e intercambiar ideas en torno a temas de actualidad que le atañen directamente. 
En orden al número de horas emitidas, la categoría infantiles es la cuarta, con 102:30 horas, $11 \%$ del total. La subdividimos en caricaturas y otros. Véase cuadro 6. Otros comprende programas híbridos integrados por concursos, juegos, personajes o entretenimientos diversos. La mayor parte de las caricaturas provienen del exterior - Estados Unidos y Japón - y de todos los géneros o subcategorías analizadas, son las que tienen el mayor porcentaje de producción extranjera:93.3\%.

\section{Cuadro 6:}

Infantiles según origen y subcategorías

\begin{tabular}{|c|c|c|c|c|c|c|c|}
\hline \multirow{2}{*}{$\begin{array}{c}\text { ssisfot } \\
\text { Subcategorías }\end{array}$} & \multirow[t]{2}{*}{ 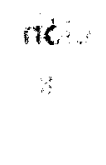 } & \multicolumn{2}{|c|}{$\begin{array}{l}\text { Producción } \\
\text { nacional }\end{array}$} & \multicolumn{2}{|c|}{$\begin{array}{c}\text { Producción } \\
\text { extranjera }\end{array}$} & \multicolumn{2}{|c|}{$\begin{array}{c}\text { Totales } \\
\text { subcategorías }\end{array}$} \\
\hline & & Horas & $(\%)$ & Horas & $(\%)$ & Horas & $(\%)$ \\
\hline Caricaturas & & $4: 00$ & 6.7 & $56: 00$ & 93.3 & $60: 00$ & 59.1 \\
\hline Otros & & $35: 30$ & 83.0 & $7: 00$ & 17.0 & $42: 30$ & 40.9 \\
\hline TOTALES ORIGEI & $V \ldots \infty$ & $39: 30$ & 38.4 & $64: 00$ & 63.2 & $102: 30$ & 100.0 \\
\hline
\end{tabular}

FUENTE: Tele Gúa Núm. 2169 y Reforma, marzo 5 a 11 de 1994.

También entre los programas dedicados a los niños hay un gran ausente: los programas culturales y educativos. Si bien en algunos de los considerados entre Otros se da cierta información, de ningún modo pueden considerarse formativos.

La televisión abierta de la ciudad destina $9 \%$ de la programación a programas educativos, destinados a jóvenes y adultos, los que para su análisis agrupamos en telesecundaria y de divulgación. Véase cuadro 7. 


\section{Cuadro 7:}

Educativos según origen y subcategorías

\begin{tabular}{|c|c|c|c|c|c|c|}
\hline tentho nol & \multicolumn{2}{|c|}{$\begin{array}{c}\text { Producción } \\
\text { nacional }\end{array}$} & \multicolumn{2}{|c|}{$\begin{array}{l}\text { Producción } \\
\text { extranjera }\end{array}$} & \multicolumn{2}{|c|}{$\begin{array}{c}\text { Totales } \\
\text { subcategorias }\end{array}$} \\
\hline Subcategorías & Horas & $(\%)$ & Horas & $(\%)$ & Horas & $(\%)$ \\
\hline Telesecundaria & $30: 00$ & 100.0 & - & - & $30: 00$ & 36.4 \\
\hline Divulgación & $34: 30$ & 65.4 & $18: 15$ & 34.6 & $52: 45$ & 63.6 \\
\hline TOTALES ORIGEN & $64: 30$ & 78.0 & $18: 15$ & 22.0 & $82: 45$ & 100.0 \\
\hline
\end{tabular}

FUENTE: Tele Guía Núm. 2169 y Reforma, marzo 5 a 11 de 1994.

Como ya se dijo, telesecundaria en el único programa estrictamente educativo, dirigido al nivel medio, con 30 horas por semana producidas por la Secretaría de Educación Pública a través de su Unidad de Televisión Educativa. Los de divulgación comprenden programas de temas diversos sobre ciencia, arte y tecnología. Cuando son locales los producen instituciones del Estado y se difunden en los tiempos oficiales que marca la ley para la programación oficial. En general los horarios destinados a este tipo de programas son los de baja audiencia.

El cuanto a los programas de variedades, dedicados al entretenimiento, ocupan el sexto lugar en la programación y fueron divididos en musicales, concursos, tele-verdad, humor y otros. Véase cuadro 8. En general, este tipo de programas son de producción local debido a que a través de ellos se promueve a artistas del momento, a la vez que permiten y fomentan la participación del público. 


\section{Cuadro 8: \\ Variedades según origen y subcategorías}

\begin{tabular}{|c|c|c|c|c|c|c|c|}
\hline \multirow{2}{*}{ Subcategorias } & \multirow[t]{2}{*}{ His } & \multicolumn{2}{|c|}{$\begin{array}{c}\text { Producción } \\
\text { nacional }\end{array}$} & \multicolumn{2}{|c|}{$\begin{array}{c}\text { Producción } \\
\text { extranjera }\end{array}$} & \multicolumn{2}{|c|}{$\begin{array}{c}\text { Totales } \\
\text { subcategorías }\end{array}$} \\
\hline & & Horas & $(\%)$ & Horas & (\%) & Horas & $(\%)$ \\
\hline Musicales & & $23: 00$ & 91.0 & $2: 30$ & 9.0 & $25: 30$ & 44.0 \\
\hline Concursos & $\varepsilon$ & $12: 00$ & 80.0 & $3: 00$ & 20.0 & $15: 00$ & 26.0 \\
\hline Tele-verdad & 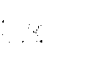 & $0: 30$ & 3.00 & $10: 00$ & 97.0 & $10: 30$ & 18.0 \\
\hline Humor & & $3: 00$ & 75.0 & $1: 00$ & 25.0 & $4: 00$ & 7.0 \\
\hline Otros & & $2: 30$ & 5.0 & - & - & $2: 30$ & 5.0 \\
\hline TOTALES ORIGEN & & 41:00 & 71.6 & $16: 30$ & 28.4 & $57: 30$ & 100.0 \\
\hline
\end{tabular}

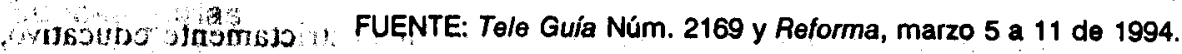

Es interesante destacar que este tipo de participación va en aumento, tanto en producciones locales como extranjeras. Sin embargo a nuestro juicio, constituye tan sólo un sustituto de la otra participación, ausente debido a que implica debatir acerca de temas controvertidos de la actualidad nacional.

Deportes fue la última categoría analizada con dos subcategorías: actividades deportivas, o sea la transmisión en directo o diferido de juegos e información deportiva. En ambos casos la producción local es alta. Véase cuadro 9.

Cuadro 9:

Deportes según origen y subcategorias

\begin{tabular}{|c|c|c|c|c|c|c|}
\hline \multirow[b]{2}{*}{ Subcategorías } & \multicolumn{2}{|c|}{$\begin{array}{c}\text { Producción } \\
\text { nacional }\end{array}$} & \multicolumn{2}{|c|}{$\begin{array}{c}\text { Producción } \\
\text { extranjera }\end{array}$} & \multicolumn{2}{|c|}{$\begin{array}{c}\text { Totales } \\
\text { subcategorias }\end{array}$} \\
\hline & Horas & $(\%)$ & Horas & $(\%)$ & Horas & (\%) \\
\hline Actividades Deport. & $27: 30$ & 69.0 & $12: 30$ & 31.0 & $40: 00$ & 75.5 \\
\hline Información Deport. & $13: 00$ & 100.0 & - & - & $13: 00$ & 24.5 \\
\hline TOTALES ORIGEN & $40: 30$ & 77.0 & $12: 30$ & 23.0 & $53: 00$ & 100.0 \\
\hline
\end{tabular}


Esta categoría puede tener variaciones muy grandes según el momento en que se analice la programación, ya que como se sabe, las transmisiones deportivas aumentan en épocas de competencias o campeonatos. El deporte en la televisión mexicana admite y propicia el debate, la controversia y la discusión de problemas de actualidad, lo cual a nuestro juicio también constituye un sustituto de otras formas y sobre todo de otros temas en los que los receptores deberían participar.

\section{Televisión de paga}

A comienzos de 1994 Çablevisión contaba con 160,000 cablehogares y 210,000 pantallas que atendían a 736,000 personas. Véase cuadro 10 . Por su parte, Multivisión declaraba 140,000 suscriptores, es decir, casi 650,000 personas. Así, ambas empresas sumaban 300,000 suscriptores, o sea, 1'380,000 personas, cifra que se obtiene al multiplicar los suscriptores por las 4.6 personas que habitan en cada hogar de la ciudad de México. (INEGI, 1992) Si como dijimos al principio, la audiencia potencial abarca a 19 millones de habitantes, tenemos que la televisión de paga alcanza sólo a 7.3\% de la población. (Crovi, 1994).

\section{Cuadro 10:}

Suscriptores de televisión de paga en el Valle de México (Diciembre de 1993)

\begin{tabular}{|lccc|}
\hline Empresa & $\begin{array}{c}\text { D. F. y área } \\
\text { metropolitana }\end{array}$ & $\begin{array}{c}\mathbf{4 . 6} \text { personas } \\
\text { por hogar }\end{array}$ & $\begin{array}{c}\text { \% del total de } \\
\text { la población }\end{array}$ \\
Cablevisión & 160,000 & 736,000 & 3.9 \\
Multivisión & 140,000 & 644,000 & 3.4 \\
TOTAL & 300,000 & 1380,000 & 7.3 \\
\hline
\end{tabular}

FUENTE: Tarifas y Datos Medios Audio-Visuales, 3/93, Medios Publicitarios Mexicanos S. A. de C. V., 1993.

No dudamos que la televisión de paga vaya día con día en aumento, pero tampoco podemos dejar de reconocer que $7.3 \%$ de la población que cubre la aparta de toda consideración masiva. Además, debido a sus costos de instalación y mensualidades, 
la pelea por ganar suscriptores en la que Cablevisión y Multivisión están enfrascadas ofreciendo más y más canales, es por un porcentaje muy bajo de la población capitalina que puede pagar por un servicio diferencial de televisión.

Cablevisión ofrecía para el mes de marzo de 1994, 23 canales más los ocho abiertos; Multivisión contaba con 20 canales más los ocho de aire. La primera empresa tiene acuerdos comerciales con Univisión y la segunda con Telemundo, entre otras cadenas. Ambas organizan su programación con base en especialidades por canales, o sea "a la carta" por lo que para analizar su oferta empleamos las mismas categorías utilizadas para la televisión abierta, pero aplicadas a los canales. No tomamos en cuenta la categoría ventas debido a que en el momento del estudio no existía ningún canal que ofreciera este tipo de programación. En cambio, se agregó la categoría otros donde incluimos los canales que ofrecen programación variada. En un estudio más profundo, valdría la pena realizar sobre estos canales de programación variada el mismo tipo de análisis efectuado acerca de los canales abiertos, sin embargo, el propósito y la extensión de estas reflexiones no es profundizar sobre ello, sino marcar las tendencias existentes. Recordemos, otra vez, que el servicio de televisión de paga llega a un escaso segmento de población mientras que el resto recibe la abierta.

\section{Cablevisión}

De los 23 canales propios que ofrecía Cablevisión 15 eran básicos, seis Premium Channels y dos de pago por evento. La suscripción costaba 45 dólares estadounidenses, la cuota mensual por los canales básicos era de 19 dólares, la cual podía alcanzar los 84 dólares según los servicios solicitados. Cabe destacar que esos 84 dólares representaban $61 \%$ del salario mínimo mensual vigente para entonces en el área metropolitana.

La categoría ficción con nueve canales (39\%) es la más atendida por la televisión de cable. Véase cuadro 11. 


\section{Cuadro 11:}

\section{- Cablevisión, canales por categoría}

\begin{tabular}{|c|c|c|c|c|c|c|}
\hline Categoría & Básicos & Premium & H. O. B. & P. P. E. & TOTAL & (\%) \\
\hline Ficción & 5 & 1 & 1 & 2 & 9 & 39.0 \\
\hline Información-opinión & 1 & $\curvearrowleft$ & - & - & 2 & 8.7 \\
\hline Infantiles & 2 & 1 & - & - & 3 & 13.0 \\
\hline Educativos & 1 & 1 & - & - & 2 & 8.7 \\
\hline Variedades & 1 & 1 & - & - & 2 & 8.7 \\
\hline Deportes & 1 & - & - & - & 1 & 4.5 \\
\hline Otros & 4 & - & - & - & 4 & 17.4 \\
\hline TOTAL & 15 & 5 & 1 & 2 & 23 & 100.0 \\
\hline
\end{tabular}

FUENTE: Perídico Reforma, 5 a 11 de marzo de 1994.

En segundo lugar con $17.4 \%$ se coloca otros, cuatro canales de programación variada en inglés. Estos canales tienen el atractivo de los noticieros generadós fuera del país, que dan un punto de vista diferente al de las televisoras locales. En tercer término se ubica la categoría infantiles con tres canales (13\%), dos básicos y uno Premium Channels.

Con dos canales, $8.7 \%$ cada una, se ubican información-opinión, variedades y educativos. La primera cuenta con un canal básico: el sistema ECO de noticias de Televisa y CNBC, destinado a información económica. Variedades llena su programación con video clips de cantantes de moda; mientras que en educativos encontramos dos canales extranjeros: Discovery y Horizonts.

Finalmente, aunque a deportes se le destina un canal (25 CableSPN), 4.5\% del total de la oferta propia de Cablevisión, este ofrece producción local, lo cual permite suponer que la empresa le confiere importancia al tema, sobre todo si lo comparamos con las demás categorías, en las que sólo ofrecen programas extranjeros o repeticiones de la televisión abierta.

Mención especial merece el manejo del idioma en Cablevisión. De los 23 canales, uno - el 21 - transmite en alemán y en ocasiones en francés. Siete lo hacen íntegramente en inglés, o sea, más de $30 \%$ de la oferta total. Además, otros siete canales mezclan programación en español e inglés.Sóloocho transmiten en español. 
De estos ocho que transmiten en español, seis pertenecen al servicio básico. El idioma ha sido un punto central de competencia entre ambas empresas de televisión de paga, lo que ha obligado a Cablevisión a subtitular algunos de sus programas para ganar suscriptores.

\section{Multivisión}

De los 20 canales propios que ofrecía Multivisión, 13 son básicos, cuatro opcionales y tres de pago por evento. Según su propia publicidad, $70 \%$ de la programación era en español, sólo dos canales transmitían íntegramente en inglés.

Desde sus orígenes Multivisión centró su competencia con Cablevisión en la oferta de programación en español y en más canales. La contratación del servicio costaba 118 dólares estadounidenses, incluyendo antena y equipo de recepción. Los pagos mensuales iban de 17 a 39 dólares al mes según el servicio requerido. Esos 39 dólares representaban $28 \%$ del salario mínimo vigente entonces. Como en Cablevisión, el costo del pago por evento varía según el programa ofrecido.

Ficción es la categoría que se coloca en primer lugar en Multivisión, con nueve canales o $45 \%$ de la oferta total. De esos, tres canales son básicos, tres opcionales y tres de pago por evento. La mayor parte de las series y el cine que programan son extranjeros. Véase cuadro 12.

\section{Cuadro 12:}

Multivisión, canales por categoría

\begin{tabular}{|lccccc|}
\hline Categoría & Básicos & Opcionales & P. P. V. & TOTAL & (\%) \\
Ficción & 3 & 3 & 3 & 9 & 45.0 \\
Información-opinión & 2 & - & - & 2 & 10.0 \\
Infantiles & 2 & 1 & - & 3 & 15.0 \\
Educativos & 1 & - & - & 1 & 5.0 \\
Variedades & 1 & - & - & 1 & 5.0 \\
Deportes & 1 & - & - & 1 & 5.0 \\
Otros & 3 & - & - & 3 & 15.0 \\
TOTAL & 13 & 4 & 3 & 20 & 100.0 \\
\hline
\end{tabular}


En segundo lugar tenemos a las categorías infantiles y otros con tres canales cada una, 15\% de la oferta. Infantiles son dos canales básicos y uno opcional los tres con series y caricaturas extranjeras. Entre ellos el canal ZAZ, básico, según la empresa televisora es el único infantil de México que ofrece su programación íntegra en español. Otros cuenta también con tres canales, todos básicos, con programación variada.

En tercer lugar se ubica la categoría información-opinión, con dos canales o $10 \%$ de la oferta. Estos son básicos y se trata de las cadenas norteamericanas CNN y NBC. La perspectiva local de la información se inserta en noticieros de los canales de programación variada o en programas especiales que suelen alcanzar gran repercusión entre sus receptores.

Con un canal cada una, $5 \%$ del total, están las categorías educativos, variedades y deportes. En educativos se ofrece un canal básico, con series de divulgación en inglés. El canal MTV básico, dedicado a video clips, integra la oferta de variedades y el MD, también básico, se dedica a deportes. Este canal ofrece un panorama amplio sobre este tema, abordando incluso aquellas disciplinas deportivas que son poco difundidas.

\section{Las tendencias dominantes}

Al comparar las categorías estudiadas en la televisión abierta con las que atiende la televisión de paga, nos encontramos que las diferencias no son muchas. Salvo en el caso de ventas, que como se dijo no se ofrece en la televisión de paga, la categoría dominante es ficción cuyas horas de emisión superan en mucho a los programas infantiles y de información-opiniòn que le siguen en orden de importancia. Educativos, variedades y deportes se ubican al final, en un nivel similar. Véase cuadro 13. 
Cuadro 13:

Programación de la televisión abierta, Cablevisión y Multivisión: porcentajes por categoría

\begin{tabular}{|lccc|}
\hline Categoría & \% Tv abierta & \% Cablevisión & \% Multivisión \\
Ficción & 34.0 & 39.0 & 45.0 \\
Ventas & 17.0 & - & - \\
Información-opinión & 16.5 & 8.7 & 10.0 \\
Infantiles & 11.0 & 13.0 & 15.0 \\
Educativos & 9.0 & 8.7 & 5.0 \\
Variedades & 6.5 & 8.7 & 5.0 \\
Deportes & 6.0 & 4.5 & 5.0 \\
Otros & - & 17.4 & 15 \\
\hline
\end{tabular}

FUENTE: cuadros 3,11 y 12

Los horarios inciden en estos porcentaje, acentuándolos. Aunque no fueron cruzados formalmente a través de cifras y porcentajes con las categoría analizadas, pudo detectarse que en los de gran audiencia, $A A A$, la televisión abierta aumenta la ficción y las noticias. Lo mismo ocurre en los canales de paga con programación variada. En cambio, los programas educativos producidos por el Estado se confinan a horarios $A$ de baja audiencia.

Sin duda la televisión mexicana, bajo la influencia de las políticas neoliberales que impulsan el libre comercio, se ha abierto al mercado rompiendo su juego monopólico y aumentando su oferta en materia de televisión de paga. Esto, no obstante, no parece asegurar una mayor diversidad de contenidos, sino que hasta el momento ha contribuido a acentuar la competencia entre las empresas televisivas que ofrecen el mismo tipo de programación. En nuestro caso, más canales no significan hasta ahora nuevas propuestas formales o temáticas, sino presentar lo mismo que está ofreciendo la competencia para intentar "robarle" su audiencia. En este sentido, las empresas televisivas antes que innovar en sus programaciones, prefieren reiterar esquemas conocidos que ya les aseguraron ganancias. En cambio, los canales culturales, aún cuando incluyen anuncios publicitarios, todavía mani- 
fiestan en la construcción de sus propuestas programáticas, esa libertad que les permite el no estar atados al rating, de la que hablábamos al principio.

Resulta sumamente difícil sacar conclusiones de un tema tan complejo como lo es la televisión, sobre todo, porque la programación, que es el caso que nos ocupa, está relacionada directamente con los canales y cadenas que la diseñan y proponen, pero también con la actitud del receptor. El extremo empresarial y organizacional, o sea la estructura de propiedad de los canales de televisión, ha sido frecuentemente estudiado, no asíla situación en que se encuentra el televidente al ver sus programas favoritos. ¿Con quién ve televisión?, icómo la ve?, ¿a qué hora?, ¿en qué lugar de la casa?, ¿con qué estado de ánimo?, son preguntas que hasta ahora tienen pocas respuestas, pero que arrojarían datos fundamentales para enriquecer cualquier estudio que se lleve a cabo sobre los contenidos de la televisión y sus efectos. No obstante las limitaciones que se derivan de analizar sólo la programación y ciñéndonos al objetivo central de este estudio, buscaremos delinear las tendencias que se advierten en la televisión mexicana, a partir de los resultados del trabajo que desarrollamos.

a) Se advierte un debilitamiento del modelo de televisión pública frente a la privada, ya que sólo $17.5 \%$ de las horas emitidas a la semana corresponden a la televisión que aún está en manos del Estado (canales 11 y 22), quedando el resto a cargo de la televisión concesionada. Estos canales públicos, por otro lado, dependen de manera creciente de la publicidad, lo cual los subordina al rating, es decir, al concepto de rentabilidad. Esto a la larga o a mediano plazo hará que el concepto previo de televisión que manejan, se identifique con la privada, produciéndose también una identificación en las programaciones, como sucedió en su momento con Imevisión y Televisa. Además, estos canales para garantizar calidad en sus programas a un costo menor que el que implicarían producciones locales similares, basan su estrategia de programación en la compra de series extranjeras, con lo que las realizaciones locales decrecen. Finalmente, respecto a la televisión del Estado, cabe destacar que el 11 ha experimentado avances sustantivos en sus tecnologías, ya que actualmente puede recibirse en todo el país, sin embargo el 22 por ser de UHF tiene una recepción deficiente, con la consiguiente pérdida de audiencia. 
b) El crecimiento de la oferta televisiva está subordinado a una concepción clasista, ya que sólo se concreta en los sistemas de paga que como advertimos, se destinan a un porcentaje muy bajo de población. Entretanto, la televisión gratuita o abierta está estancada. Así, el principio de libre empresa promovido por el neoliberalismo sólo se ha practicado entre los sistemas restringidos, mientras que en el abierto los cambios operados se derivan de las privatizaciones.

c) La tasa de ganancia determina los objetivos de los canales y empresas televisivas, tanto privadas como del Estado, por lo que los contenidos se subordinan a ella. Esto significa que el concepto previo de televisión que se tiene en la ciudad de México al elaborar una programación, está determinado por su rentabilidad. Concepto que, por otra parte, va borrando los escasos límites que aún subsisten entre la televisión pública o del Estado y la privada.

d) En cuanto a la programación, tenemos que la ficción es el género más programado por la televisión mexicana, lo cual la perfila como una televisión de entretenimiento, tendencia que en los últimos tiempos parece definir el sentido de la televisión de casi todo el mundo. Esto no significa, sin embargo, que el medio pierda su fuerza, su penetración y menos aún su influencia cultural. A partir de este reconocimiento, algunos países han buscado promover producciones independientes que equilibren los contenidos televisivos o mantienen una actitud vigilante mediante asociaciones de usuarios para defender una mayor equidad programática. En México aún no se llevan a cabo acciones de ese tipo, por lo que el desafío es desarrollar ese tipo de acciones, que permitan a futuro contar con una televisión diferente de la que hoy en día se nos ofrece.

e) La categoría ventas ocupa un ostentoso segundo lugar en la distribución de tiempos de la programación. Este tipo de programas deberían, a nuestro juicio, confinarse a los servicios de paga como un canal temático, pero nos parece excesivo que habiendo sólo ocho canales abiertos en la ciudad de México, uno esté prácticamente destinado a vender productos superfluos en una sociedad con graves problemas económicos en la mayor parte de su población.

f) Casi $35 \%$ de las horas emitidas se producen fuera del país, además, buena parte de los programas locales recurren a fuentes extranjeras o se destinan a públicos internacionales. Sin duda la globalización económica y el fortale- 
cimiento de los monopolios mediáticos ha acelerado ese proceso de trasnacionalización, pero aún así y tal como se ha hecho en otros sectores de la economía, es necesario delinear medidas que protejan las producciones nacionales en varios sentidos, entre los que destacan: fuentes de trabajo, preservación de la cultura e identidad nacionales y derechos de autor.

g) De manera colateral y sobre todo a partir del monitoreo paralelo realizado junto con el análisis de la programación, se desprende que la televisión mexicana no permite la participación del público en los programas, salvo cuando se trata de variedades, específicamente concursos, humor o musicales. Esta participación, a nuestro juicio, constituye un sustituto de la que debería realizarse en debates sobre los problemas actuales del país, en los que el ciudadano común ejerza sus derecho de expresión y denuncia. En este sentido la radio ha tomado la delantera, incorporando la voz de sus receptores, lo que junto con otras razones, le ha permitido ir desplazando a la televisión, sobre todo en el aspecto noticioso y en lo que se conoce como "radio hablada", es decir, análisis en torno a temas diversos de actualidad.

h) El público infantil, muy amplio en México, recibe atención destacada en la televisión abierta y de paga, pero la mayor parte de los programas son extranjeros. Los pocos que se realizan a nivel local están profundamente permeados por los anuncios publicitarios, de suerte que no se puede reconocer donde empiezan los comerciales y dónde acaban los segmentos que componen el programa. Urge, como se está haciendo ya en otros países, exigir la defensa de los derechos de los menores y proteger, no sólo con horarios, los contenidos de programas infantiles.

i) Una de las características más destacada y novedosa de las programaciones televisivas es la creciente ruptura de los géneros, sobre todo, al mezclar información y opinión, o ficción y realidad.

Si como afirma Josefina Vilar el género existe como una institución histórica y cultural, por lo que puede considerarse un horizonte de espera tanto para quien elabora el mensaje como para quien lo recibe, al romperse ese horizonte en la actualidad la televisión está llevando peligrosamente a confundir los límites entre ficción y realidad, información y opinión. Prueba de ello son los reality shows que recrean a través de ficción hechos verídicos, o los noticieros aparentemente "informativos" que deslizan una y otra vez el comentario casi siempre tendencioso sobre la realidad nacional o interna- 
cional. La creación de culpables, el señalamiento de ciudadanos, la expiación pública a través de la denuncia mediática, entre otras acciones, se ven favorecidas por esta creciente ruptura de géneros que viene acompañada por las enormes posibilidades que día con día ofrece la tecnología a las producciones televisivas.

j) Como comentario final, cabe agregar que los datos que acabamos de presentar nos indican que estamos sólo ante un incompleto punto de partida; ya que se trata de un estudio que requiere continuidad para determinar tendencias permanentes, así como ajustar aspectos metodológicos y operativos. Creemos además, que este tipo de análisis debe complementarse con estudios cualitativos realizados entre la audiencia, para determinar aspectos de la recepción que trascienden al análisis de la programación.

\section{Referencias bibliográficas}

Crovi DruetTA Delia (1993): “Televisión y libre comercio...Fantasía de diversidad". Revista Mexicana de Ciencias Políticas y Sociales Núm. 154 (octubre-diciembre). México: UNAM/FCPyS.

(s. f.): "Televisión y neoliberalismo en México" (Tesis de doctorado en Estudios Latinoamericanos). México: UNAM/FCPyS.

INEGI (1992): Censo Nacional de Población. México: Aguascalientes.

PERIÓDICO REFORMA (1994): Núms, del 5 al 11 de marzo.

TELE GULA (1994): Año 42, Núm. 2169, marzo.

VILAR Josefina et al (1988): El sonido de la radio. México: UAM-X/Imer/Plaza y Valdés.

WISA (1992): Plano mercadológico y económico, México D. F. y área metropolitana. México. 